Divers@ Revista Eletrônica Interdisciplinar,

Matinhos, v. 14, n. 2, p. 1-5, jul./dez. 2021

ISSN 1983-8921

doi: http://dx.doi.org/10.5380/diver.v14i2.84183

\title{
EDITORIAL: EDUCAÇÃO, BUEN VIVIR E SABERES DECOLONIAIS
}

\author{
Ana Josefina Ferrari ${ }^{1}$ \\ Luiz Fernando de Carli Lautert ${ }^{2}$
}

Para o Onas, na Terra do Fogo, sul da Argentina, quem criou o mundo foi Timáukel, o ser supremo. Ele criou tudo já que o mundo era muito diferente do que é hoje. O mundo, antes de Timáukel, era uma superfície dura sem montanhas, sem rios e sem mar, era tudo seco, deserto e silencioso e nada vivia no mundo. O céu, muito baixo, parecia que se aplastava sobre a terra e o céu, o céu não tinha estrelas nem sol nem lua. Foi então que Timáukel criou a Kinós que foi encarregado de fazer daquele mundo deserto e sem vida um lugar para viver.

Kinós foi criando árvores e plantas e animais e montanhas e homens também, todos eles vieram da criação de Kinós. Não havia diferenças entre todas as criaturas de Kinós, os elementos se conjugavam para que as criações/ criaturas existissem. Kinós envelheceu e quando estava já muito cansado e velhinho, se envolveu no seu manto de pele e ficou quietinho, como dormindo. Ficou desse jeito alguns dias, dormitando. Quando acordou, era jovem novamente. Os outros seres humanos também fizeram o que Kinós fez e eles nunca morriam, até que Chénuke, um dos habitantes, foi descansar e nunca voltou, virou a primeira estrela do céu. Assim contam os Onas, no fim do mundo, a história do começo do mundo.

Esta história nos traz vários elementos para pensar: a separação do céu e da terra, a divisão das espécies, a divisão dos homens, o afastamento do ser humano, do filho urbano industrial/moderno da mãe Terra. Nas narrativas fundacionais, não só dos Onas como de muitos povos originários, encontramos que não há divisão ou separação neste mundo e não há superiores ou inferiores.

As narrativas dos povos do altiplano, da Amazonia, da Patagonia, das diferentes regiões do continente africano não fazem essa distinção, ele surge em outros povos com outras histórias, ela surge em povos que habitavam o continente europeu. Estes povos, que viveram no continente europeu, no final do Século XV, iniciaram seus movimentos de ocupação de novas outras terras. Este processo o conhecemos como colonização. Este movimento de ocupação não foi pacífico, foi de extrema violência, física, material e simbólica. A partir desses movimentos de colonização nos quais o extermínio e a extração foi um dos seus traços principais, estabeleceu-se uma cultura e uma estrutura sócio-política que denominamos de Colonialismo.

Este período Colonial tem seu início no Século XV e chega até nossos dias, muitos dos elementos simbólicos deste momento, que podemos considerar fundacional, ecoam até hoje e constituem o que se denomina a colonialidade do poder, do ser, do sentir, do saber, do território e do corpo. Podemos ouvir esses ecos no trato com as comunidades indígenas, comunidades afrodescendentes, com o lugar que habitamos, com o espaço no qual somos.

O Choque entre essas culturas, a diferença intercultural de pensamento entre Europeus e povos originários, pode ser captado nas mensagens da família de jogos de mancala criados no continente Africano . Estes jogos propõem diferentes formatos que estimulam o raciocínio, a elaboração de estratégias, a relação com a vida e o mundo e a forma de sentir e agir. Os jogos de Mancala apresentam princípios como a circularidade, a ancestralidade, a

\footnotetext{
${ }^{1}$ Professora do Curso de Licenciatura em Linguagem e Comunicaçãoe do Programa de Pós-Graduação em Rede Nacional para o Ensino das Ciências Ambientais (Profciamb), Universidade Federal do Paraná, Setor Litoral (UFPR Litoral), Matinhos/PR, Brasil.e-mail: ana.josefina@gmail.com Orcid https://orcid.org/0000-0002-9273-7709

${ }^{2}$ Graduado e Mestre em Geografia, Doutor em Ciências, Professor do Curso de Licenciatura em Ciências e Profciamb, UFPR Litoral, Matinhos/PR, Brasil. e-mail: luizlautert2@gmail.com Orcid https://orcid.org/0000-0002-5905-0198
} 
memória, a corporeidade e o corporativismo. Estes elementos contidos no jogo são originários do pensamento afro centrado, do berço da humanidade com mais de 20 mil anos de história, e que depois se espalharam pelo mundo através da diáspora Africana, e para Abya Yala/ América e através do estreito de Bering.

Esses princípios foram substituídos pelo conflito, competividade, raça, patriarcado na aniquilação manipulação total do outro do inimigo, das raças inferiores, propostas pela colonização Europeia. Enquanto no Mancala o adversário não pode ficar sem sementes no tabuleiro porque a interação com o oponente o faz evoluir e vencer; na Coloniedade/ Modernidade a única estratégia é aniquilar quem estiver na frente e atribuir às raças o estatuto de inferiores sem interesse pelas consequências.

O domínio total da Natureza, a pilhagem dos seus componentes, bióticos e abióticos, e a dessacralização da natureza pela Colonialidade/Modernidade, transformou água, terra, fogo e ar em mercadorias, em produtos mercantilizáveis. A Prata extraída de Potosí, na Bolívia, nos primeiros 300 anos de pilhagem, supriu grande parte da demanda de Prata no mundo. As águas antes livres nos rios e nos quintais, hoje são poluídas e privatizadas pelos movimentos neoliberais, que se instalam para continuar a exercer o processo de apagamento das culturas dos povos originários e tradicionais "Del Sur".

Na conferência de Glasgow, que aconteceu em Escócia em novembro de 2021, os diferentes líderes mundiais discutiram a respeito dos diversos danos ambientais que estamos sofrendo e qual será nosso destino se continuamos neste caminho, nesta relação entre seres humanos e com nosso lugar, o planeta.

Em certo modo, as perguntas que surgem o tempo todo são: o que queremos fazer com o futuro? o que desejamos deixar para as próximas gerações? O modo de economia capitalista é muito claro ao propor produzir e consumir até exaurir, mas é isso o que queremos? O Modelo de desenvolvimento atual nos levará à prosperidade ou ao colapso? A pôs modernidade está conseguindo responder às perguntas e agir à altura que as mazelas e os desafios que a crise ambiental nos impõe? Quais serão os cenários futuros: prosperidade ou extinção? O planeta terra já passou por diversas extinções que acabaram com $90 \%$ de toda a vida no planeta.

Acreditamos que existem alternativas ao modelo de desenvolvimento e Educação centrados na Colonialidade/ Modernidade, elas são possíveis, elas são alternativas à colonialidade do poder, do Saber e do Viver. Alternativas como o movimento sócio cultural e filosófico do Buen Vivir, caracterizado pela relação a com a natureza. Os povos originários de Sul a Norte são um exemplo de como somos capazes de responder às crises, às dificuldades impostas pelos processos com resiliência.

A proposta do presente dossiê é o resultado de uma série de discussões e conversas realizadas no escopo do mestrado Profissional de Ciências Ambientais da UFPR Setor Litoral. Ele visa trazer diferentes perspectivas sobre as temáticas a respeito do meio ambiente, as políticas e saberes decoloniais, o pós colonialismo em diálogo com a Educação ambiental crítica, a educação popular e o Buen vivir. É um dossiê multi, trans e interdisciplinar. Os artigos discutem a relação que o ser humano estabelece com e na Natureza. Nossa proposta é apresentar trabalhos que debruçam seu olhar para novas perspectivas (paradigmas alternativos) e para as relações sociais; as relações da sociedade com a Natureza; estudos do Buen Vivir; dos Bens Comuns e dos saberes decoloniais e de suas práticas na área de Educação no Brasil e na América Latina.

Assim sendo, Renata Soares Kellermann e Paulo Rogério Lopes no seu texto "Educação libertária e tecnologias sociais como ferramentas para a transição agroecológica" nos relatam a experiência realizada em um módulo da UFPR Setor Litoral denominado Interações Culturais e Humanísticas no qual foi tratado o tema da Transição Agroecológica. Os autores descrevem como, a partir de encontros remotos, reuniram docentes, discentes, colaboradores e comunidade não acadêmica, que compartilharam suas experiências agroecológicas visando, a partir desta partilha, encontrar outros caminhos que nos levem a uma transição social, ambiental, ética e econômica tão necessária para a Terra e, principalmente, para os setores menos assistidos e favorecidos da sociedade.

Ana Christina Duarte Pires, no seu artigo "Agroecologia como educação para o bem viver", nos traz um conjunto de reflexões que partem do entendimento das bases da Agroecologia a fim de sustentar transformações que nos aproximem do Bem Viver. A autora considera que a Agroecologia, deste modo, amplia seus conceitos para além da produção de alimentos, incluindo dimensões como ciência e estilo de vida. Partindo destas 
afirmações, ela inicia uma discussão a respeito do Bem viver e suas possíveis materializações em ações concretas entendendo que, nesse processo educativo e alternativo e emancipatório, a recuperação da sabedoria instintiva, a capacidade amorosa, a criatividade e o reconhecimento do território, das pessoas, dos grupos e da natureza é fundamental. Ana Christina, para concluir, nos faz um convite à transformação através de ações viáveis e reais com comprometimento.

Helio Augusto Teixeira Silva e Kerley dos Santos Alves no texto denominado "Buen vivir - suas origens e consolidação na América do Sul" se propõem, por meio de uma pesquisa bibliográfica e documental com análise de artigos científicos, avaliar o equilíbrio entre o progresso da humanidade e a preservação da natureza. Desse modo, os autores procuram compreender como o Buen Vivir foi incorporado na legislação brasileira. Para tal, analisaram alguns princípios constitucionais e ambientais que se aplicam à matéria da proteção ambiental. Silva e Alves concluem que a Filosofia do Buen Vivir, também foi incorporada na Constituição brasileira através de diversos mecanismos e recursos legislativos.

Edna De Meira Coelho e Nicolle Cloé Nassur, no artigo “Aproximação entre a educação popular no MST e bem viver", se propõem fazer um relato a respeito das aproximações entre a Educação Popular no MST e Bem Viver. Elas objetivam apresentar argumentos para promoção de uma confluência dos dois movimentos. Coelho e Nassur concluem que o ser humano precisa de raízes as que só consegue produzir quando se encontra em coletividade.

Luiza Breis, no artigo "Ensino decolonial aos educadores do campo: uma perspectiva da licenciatura em educação do campo da UFPR”, pretende, a partir de uma metodologia fundamentada na pesquisa teórica e descritivo-exploratória, analisar a proposta do Projeto Pedagógico do curso de Licenciatura em Educação do Campo (LeCampo), da Universidade Federal do Paraná. A autora considera este documento como ferramenta de ensino-aprendizagem decolonial. Através dos quatro apartados do texto, a autora percorre desde os estudos decoloniais na América Latina até as especificidades do Projeto Pedagógico do curso LeCampo. Conclui que o documento tem o funcionamento de multiplicador do pensamento decolonial, fortalece a emancipação do pensamento euro centrado e fortalece o processo de aceitação dos estudantes enquanto latino-americanos.

Vandra Feretti, Angela Jeane Salles Rodrigues, Roberta Geovanna Cavalheiro Alvim, Fernando Luiz Ramos Brock, Marcos Joel Vaccarelli, Helena Midori Kashiwagi, Roberto Eduardo Bueno e Manoel Flores Lesama apresentam o texto "Interdisciplinaridade e educação ambiental em período de ensino remoto". No mesmo, os autores relatam a investigação realizada com estudantes, do município de Matinhos, de uma turma do $9^{\circ}$ ano e outra da $1^{a}$ série do Ensino Médio nas turmas de Matemática e de Ciências, respectivamente, os quais foram participantes de aulas ministradas a partir de docência compartilhada. Desse modo, foi realizada uma análise comparativa, pela técnica de Análise de Conteúdo, de questionários elaborados a partir de uma abordagem qualiquantitativa e encaminhados de modo remoto. A partir deste trabalho na escola, os autores observaram um aumento no percentual de estudantes que percebem o ser humano como parte da natureza. Os mesmos concluem que este fato se deu pelo uso da metodologia de docência compartilhada que, dentre outras questões, favoreceu o diálogo, dinamizando e estimulando a comunicação e contribuindo para a formação de sujeitos críticos com capacidade de argumentar e tomar decisões pertinentes sobre questões socioambientais.

Elaine Ribeiro e Ana Josefina Ferrari no artigo "O silêncio da educação ambiental na Base Nacional Comum Curricular: uma análise do efeito de deslizamento sofrido pelo termo na BNCC" apresentam o resultado parcial da pesquisa de mestrado. As autoras farão uma análise do Caderno de Ciências da Natureza da BNCC, procurando os efeitos de sentido que o termo Educação Ambiental produz nele. O objetivo das autoras é apresentar tanto a análise feita do termo Educação Ambiental no texto da BNCC quanto as análises que mostram o deslizamento de sentido que o termo EA sofre nas diferentes sequencias da normativa. Perante a ausência de ocorrências do termos, Ribeiro e Ferrari concluem que o termo sofre um silenciamento, se perguntando, então, a que sujeitos interessa o silenciamento de debates e reflexões críticas nos currículos escolares, de temáticas tão importantes e urgentes?

Gisele Paiva Lima, Fábio de Carvalho Messa e Kayan Gusmão no trazem o texto "Literatura e educação ambiental: uma possibilidade de diálogo" no qual se propõem apresentar uma sequência didática construída por eles e que envolve práticas de leitura literária e reflexão voltadas à Educação Ambiental Crítica. O conjunto de atividades foram aplicadas em uma escola de Matinhos, em um nono ano. A atividade visou trabalhar a Educação Ambiental Crítica através de textos literários, considerados estes como instrumentos pedagógicos. 
A obra escolhida para o trabalho foi O Voluntário, de Inglês de Sousa, escritor paraense pertencente à escola literária naturalista. Cinco momentos compreenderam a sequência mencionada e recortes de alguns desses momentos são apresentados no artigo visando observar os repertórios pré-existentes dos alunos e investigar possíveis ressignificações.

Parley Lopes Bernini Silva, Érica Arruda Peluzio e Sheila Maria Doula "Panorama da pós-graduação em extensão rural: desafios e perspectivas contemporâneas" nos trazem um levantamento bibliográfico e documental junto a Secretaria de Pós-graduação do programa Strictu Sensu do Centro de Ciências Agrárias da Universidade Federal de Viçosa. Os autores analisaram 641 matriculados procurando compreender o motivo pelo qual os estudantes procuram realizar o curso.

Viviane Camejo Pereira e Claudemira Vieira Gusmão Lopes, no artigo "O ecologismo dos pobres e o racismo ambiental: reflexões sobre sociedade e natureza para uma educação ambiental crítica”, realizaram uma revisão bibliográfica, procurando observar o processo de exclusão que relega as populações tradicionais do campo, das águas e das florestas e as populações economicamente vulneráveis nas periferias das grandes cidades a áreas mal conservadas e exploradas. Nestas áreas, a desigualdade se faz presente em termos sociais e ambientais, conflitos decorrentes de um modelo de desenvolvimento denominado por elas com insustentável.

Indiamara Hummler Oda, no texto "Os saberes das pescadoras e pescadores artesanais: um aprendizado emancipatório", procura, a partir de uma metodologia etnográficadar visibilidade ao modo de acontecimento das práticas pesqueiras artesanais no Litoral do Paraná. De acordo com a autora, essas práticas coexistem e resistem com/a uma economia capitalista. Indiamara analisará as narrativas destes caiçaras.

Tanice Massuchett, Elizangela Sarraff e Maurício Fagundes no artigo "A formação e trans-formação do professor na busca de uma educação libertadora" problematizam, por meio de uma pesquisa de base qualitativa e bibliográfica da obra de Paulo Freire, a ação e a formação permanente do professor em uma perspectiva libertadora. Ao longo do trabalho, os autores observam como a educação popular permite a superação da educação bancária e propicia o processo da práxis através do qual o docente é inserido em um processo de (trans) formação permanentes, indispensáveis nos nossos dias.

Aldo Ocampo González, no seu artigo "Y-cidad de la educación inclusiva", tem o objetivo de desenvolver o conceito Y-Cidad e o de Educação Inclusiva, o qual se contrapõe em muitos pontos com o de Educação Especial. $\mathrm{O}$ autor conclui, no seu artigo, que a inclusão deve avançar no sentido que possibilite aprofundar as diferentes dinâmicas e os processos de singularização revisando os sistemas categoriais vigentes.

Jamile Wayne Ferreira, no seu texto "Das estrelas que não vemos: conceito, feminismo e poluição luminosa", procura debater a respeito dos caminhos epistemológicos do feminismo. A autora fará um percurso histórico analisando os efeitos dos diferentes movimentos do movimento observando como eles se entrecruzam, alimentam e retroalimentam.

O conjunto de artigos aqui apresentados representam algumas das discussões que, na atualidade, circulam nos âmbitos das áreas de Educação, Educação Ambiental, Letras, Sociologia, dentre outras.

Esperamos que gostem da leitura.

Os Organizadores. 
Editores Chefes

Diomar Augusto de Quadros, Universidade Federal do Paraná (UFPR), Brasil

Paulo Eduardo Angelin, UFPR, Brasil

Secretária Executiva

Valéria dos Santos Oliveira, UFPR, Brasil
Editores Associados

Elsi do Rocio Cardoso Alano, UFPR, Brasil

Gabriela Schenato Bica, UFPR, Brasil

Silvana Cassia Hoeller, UFPR, Brasil

Bibliotecária-Documentalista

Simone Ferreira Naves Angelin, UFPR, Brasil 